\title{
Robustness of large-span timber roof structures - Two examples
}

\author{
Jørgen Munch-Andersen ${ }^{\mathrm{a}}$, Philipp Dietsch ${ }^{\mathrm{b}, *}$ \\ a Danish Timber Information, Lyngby Kirkestræde 14, DK-2800 Kgs. Lyngby, Denmark \\ ${ }^{\mathrm{b}}$ Chair for Timber Structures and Building Construction, Technische Universität München, Arcisstr. 21, D-80333 Munich, Germany
}

\section{A R T I C L E I N F O}

\section{Article history:}

Available online $\mathrm{xxxx}$

\section{Keywords:}

Timber

Structure

Large span roof

Failure

Robustness

Redundancy

Indeterminacy

\begin{abstract}
A B S T R A C T
This paper discusses the robustness of large-span timber roof structures, based on findings from failures of two roof structures. One is the Siemens arena in Ballerup, Denmark and the other the Bad Reichenhall ice-arena in Germany. The structures are described as well as the flaws that are believed to have caused the failures. The two cases serve as examples of different design strategies for large-span timber roof structures and the consequences of such strategies for robustness. It is demonstrated that robustness is not a straightforward concept because the best strategy depends on the cause of the failure - which was obvioûsly not known during planning and design.
\end{abstract}

(c) 2011 Published by Elsevier Ltd

\section{The structures and their failures}

\subsection{Siemens arena}

The cycling arena was built in 2001. The main roof structure consisted of 12 trusses, each truss composed of two glulam timber arches with vertical connectors, see Fig. 1. The upper arch was mainly exposed to compression, the lower arch to tension. The horizontal components of the tension and compression forces were neutralised at the corner connections, realised with concealed steel plates which were connected to both ârches by embedded dowels and a few bolts, see Fig. 2. The structure appeared as an elegant slim construction with a free span of 73 metres across the arena. The distance between the trusses was 12 metres. The secondary structure consisted of simply supported purlins.

Two of the trusses collapsed without warning at a time with almost no wind and only a few millimetres of snow. The partial collapse happened just a few months after the inauguration of the arena. No people were present in the arena during the collapse.

An investigation, see [1], showed that the cause of the failure could be localised to one critical cross-section in the tension arch near the support, where the load bearing capacity was found to be between $25 \%$ and $30 \%$ of the required capacity, see Fig. 3. By mistake, this cross-section was not considered at all in the design. Three critical design errors were identified:

\footnotetext{
* Corresponding author.

E-mail addresses: jma@traeinfo.dk (J. Munch-Andersen), dietsch@bv.tum.de (P. Dietsch).
}

- The design strength used for the timber part was almost $50 \%$ too high.

- The reduced height of the cross-section near the ends of the arches, see Fig. 2, was not considered.

- The reduction of the timber cross-section due to steel plates, bolts and dowels, see Fig. 3, wâs not considered.

The expected short term load-carrying capacity at the critical cross-section happened to be only slightly larger than the loads from the self weight of the structure. Because the strength of timber is reduced over time when it is loaded (the $k_{\text {mod }}$-effect), it is likely that the collapse took place when the strength was reduced tue to the stresses caused by the self-weight. According to Eurocode 5 [2] and confirmed by Hoffmeŷer and Sørensen [3], the reduction factor for medium duration loads ( 1 week to 6 months) is $k_{\text {mod }}=0.8$. Such a reduction is enough to explain how the collapse could take place at a time with no special external load.

The investigation also revealed that the stability of the trusses was not ensured sufficiently and that the quality of the gluing of the glulam was not as specified. These problems, nevertheless, did not contribute to the actual failure.

The collapse did not occur due to an unknown phenomenon. The design of the trusses was not checked by the engineer responsible for the entire structure due to unclear specification of the responsibility and duties of that engineer. This might explain why such a vital error could pass the quality assessment of the design. The demands to the quality assessment of such structures in the Building Regulations have been increased after the incident. An independent third party control is now required.

0141-0296/\$ - see front matter (C) 2011 Published by Elsevier Ltd doi:10.1016/j.engstruct.2011.03.015 


\section{$A R T C L E$ E IN PRESS}

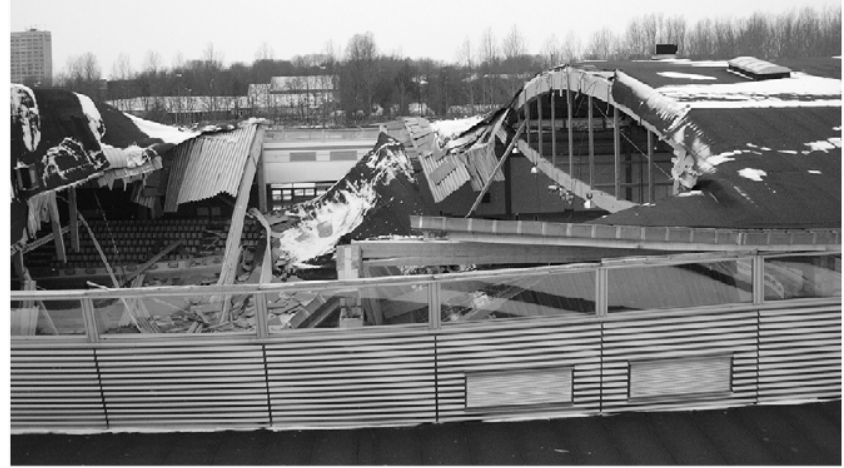

Fig. 1. The Siemens arena roof structure after the collapse of two trusses. An intact truss can be seen on the right.

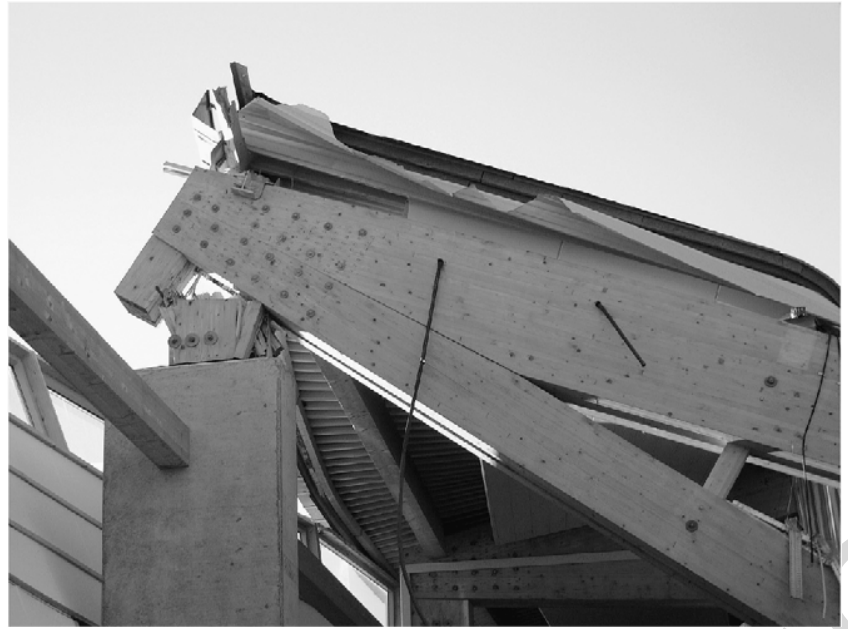

Fig. 2. Corner connection with concealed steel plates, connecting the timber parts through bolts (visible) and dowels (not visible).

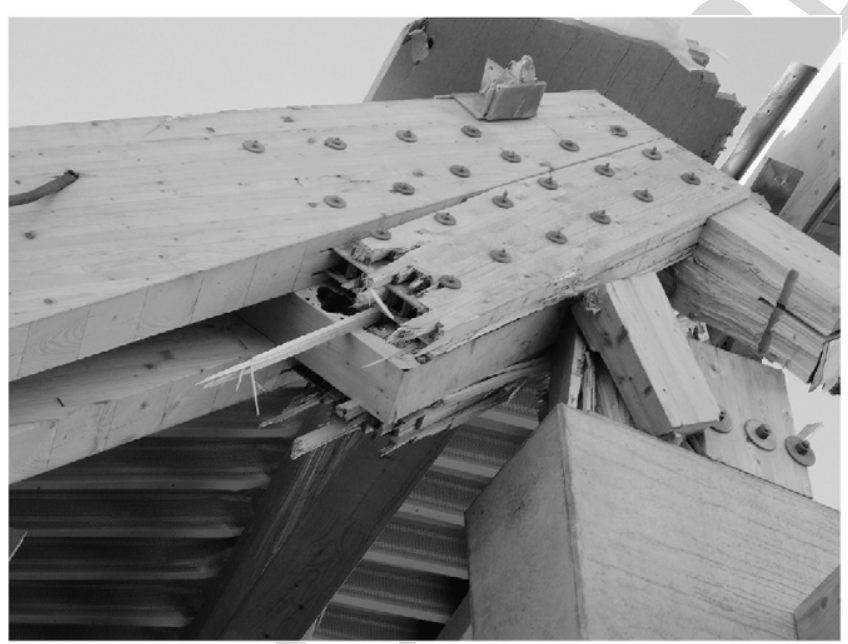

Fig. 3. Rupture at the critical cross-section in the corner connection. Note the dowels and steel plates.

\subsection{Bad Reichenhall ice-arena}

The contents of the following are derived from Winter and Kreuzinger [4]. A description of the structure from both architectural and structural points of view is given in [5].

The Bad Reichenhall ice-arena, built in 1971/1972, was a structure of approx. $75 \mathrm{~m}$ in length and approx. $48 \mathrm{~m}$ in width,

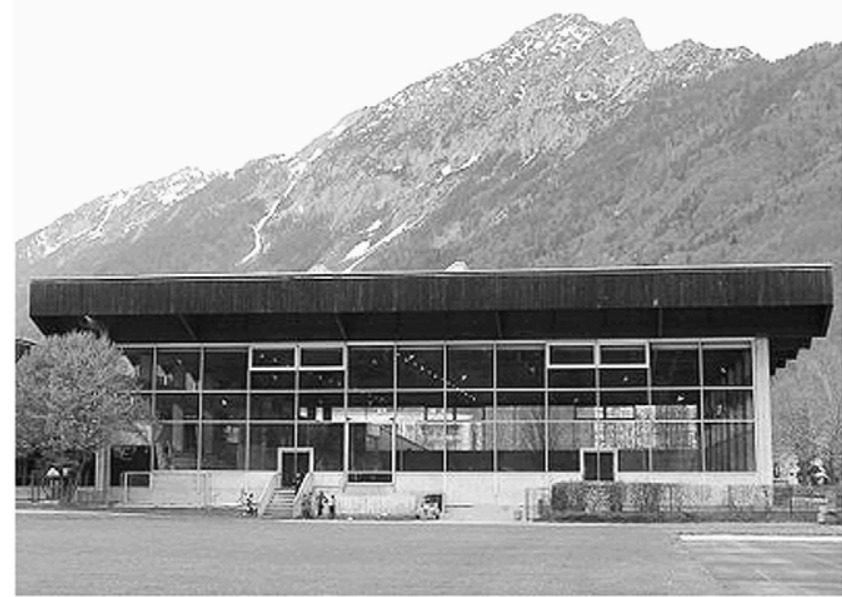

Fig. 4. The ice-arena in Bad Reichenhall.

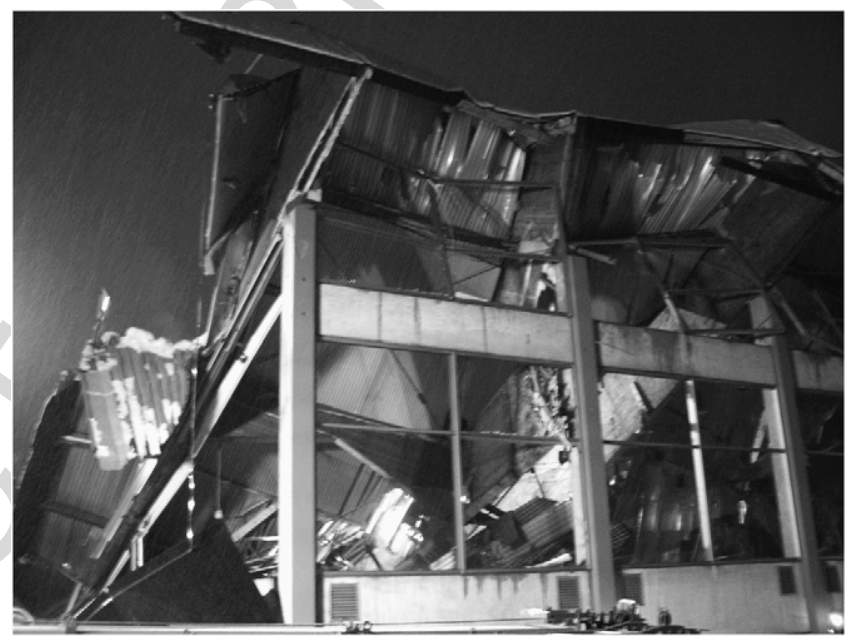

Fig. 5. Partial view of the collapsed roof structure.

see Figs. 4 and 6. The roof was supported by $2.87 \mathrm{~m}$ high main girders, which were produced as timber box-girders, see Fig. 7. The box-girders featured upper and lower glulam members and lateral web boards made from so-called "Kämpf web boards" - a type of cross-laminated timber. The $48 \mathrm{~m}$ long girders were produced from three $16 \mathrm{~m}$ long sections, which were joined with general finger joints [5].

The secondary system was fixed to the sides of the girders and acted both as purlins and as lateral bracing ( $K$-bracing) for the main box-girders, see Fig. 6 . This enabled the roof structure to redistribute loads between the girders.

On January 2nd 2006, the entire roof collapsed - without warning - during a period of significant snowfall, see Fig. 5. However, the snow load was not above the characteristic snow load used in the design.

The design and construction of the girders were identified as one cause for the failure. There were several contributions to the failure:

The review of the structural calculations revealed two important errors. For the assessment of the load-bearing capacity of the box-girder, the bending strength of the glulam was applied, rather than the tensile and compressive strength of the lower and upper girders. In addition, the weakening of the cross-sections due to the general finger joints between the girder parts as well as the web-boards was not taken into account in the structural calculations. Comparative calculations, based on the technical rules 


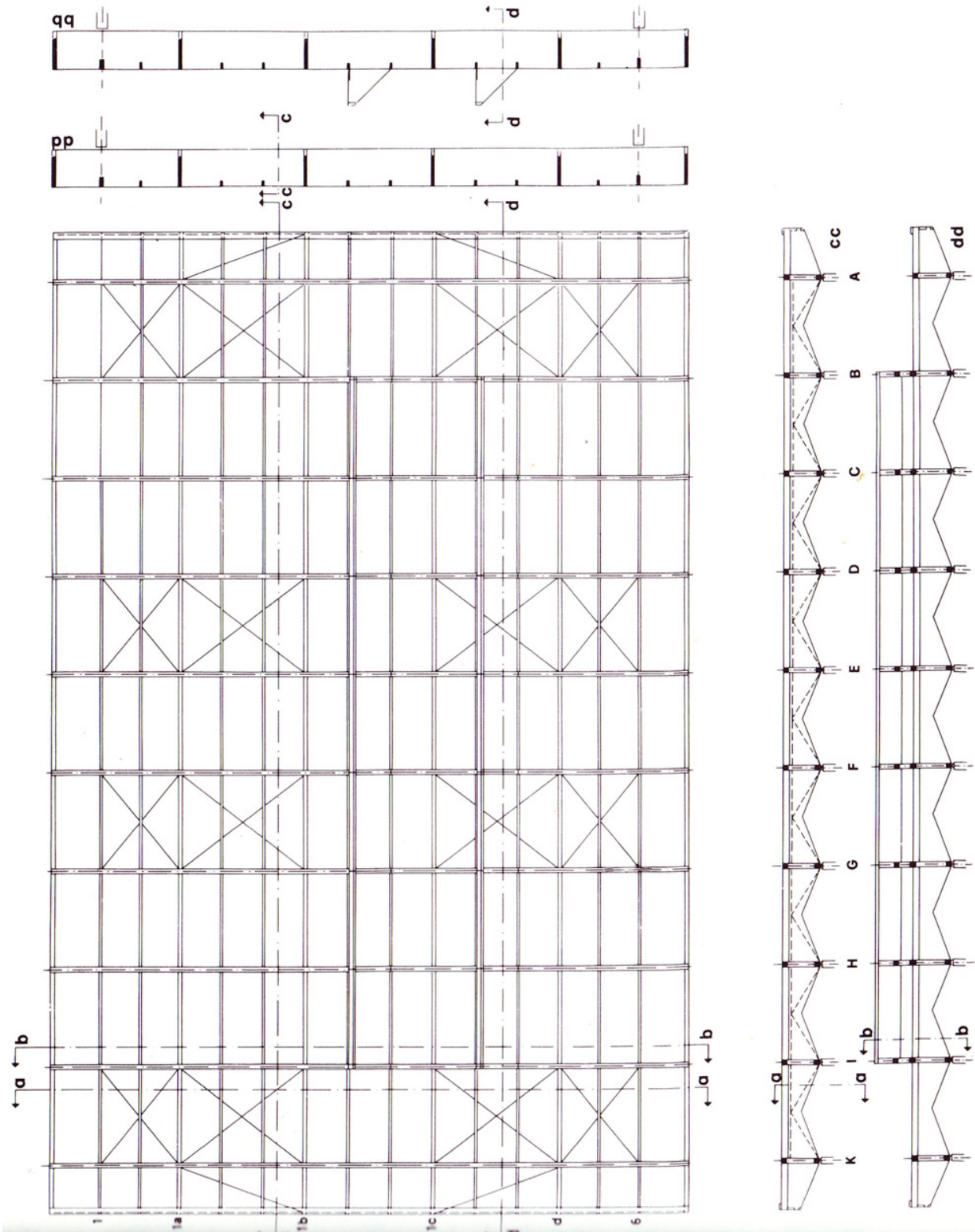

Fig. 6. Layout of the roof of the ice-arena and side view of the girders (from [5]).

applicable at the time of the construction of the Bad Reichenhall ice-arena, have shown that the safety factor was only of a magnitude of around 1.5, whereas the required factor was about 2.0.

For the box-girder with Kämpf web-boards, a general technical approval was available, which however limited the height of the web-girders to $1.20 \mathrm{~m}$. Therefore, a so-called "Approval for an Individual Case" by the Supreme Building Authority would have been necessary for executing this special structure. According to the findings to date, such an approval was not applied for. An application from 1971 to extend the general approval to larger heights was not granted by the German Institute for Building Technology. Further, the production of the vertical general finger joints of the web-boards must be regarded as difficult and not very robust. The quality of the glue lines in these finger joints differed significantly.

The box girders were produced using a urea-formaldehyde glue. The technical rules both then and now allow the use of this type of glue for load-bearing components only in a dry ambient climate because that glue is not permanently moisture-resistant.
Today, it is known that unheated and non-air-conditioned icearenas represent a particularly critical climate for moisturesensitive components. Besides a high relative humidity, the thermal radiation between the ice surface and the roof parts facing the ice surface leads to cooling and thereby increased condensation on these parts of the roof structure. Since that knowledge did not exist in 1972, the use of urea-formaldehyde glue for bonding the load-bearing components did not generally violate the state-ofthe-art of technology at that time. However, the general technical rules for using the Kämpf web-boards required the connections between the glulam-girders and the web boards to be carried out with the significantly more elastic resorcinol glue $(\mathrm{RF})$, due to the thick bonding gaps.

The gluing of the blocking between girders and web-boards at the supports did not correspond to the recognised rules at the time since gluing secured by nails was and is limited to a board thickness of max. 35-50 mm.

Due to the humidity exposure over the years, the glue-lines and finger joints were significantly damaged. This primarily affected 

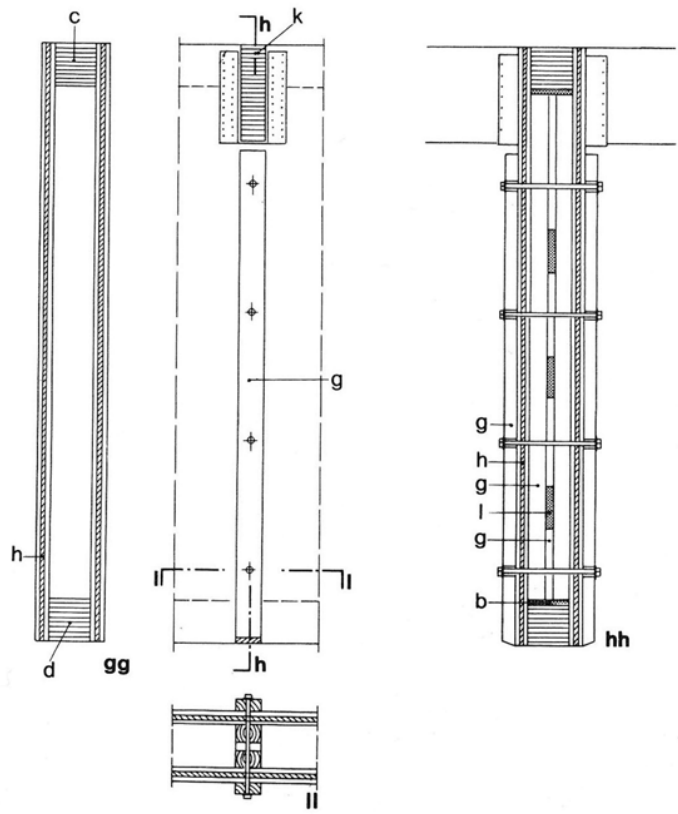

c-upper girder, d-lower-girder, h-Kämpf web-board, k-purlin, g-reinforcement (to avoid buckling)

Fig. 7. Cross-section of the box-girders in the ice-arena (from [5]).

the general finger joints in the lower girder and the bonding between the girders and the web-boards. It was found that in some cases, there was no adhesive effect to a depth of $50-80 \mathrm{~mm}$ in the lower girders. In combination with the errors in the structural calculations, this represents the most significant cause for the collapse of the Bad Reichenhall ice-arena.

In addition, there were repeated cases of water penetration as a result of leaks in the roof membrane and in the area of the roof drainage. These were not permanently rectified and the roof structure did not receive renovation paint during the use of the arena. Whether such measures would have significantly delayed the damage to the glue lines of the roof structure cannot be answered.

The structural calculations for the roof structure appear not to have been examined by a check engineer, even though this was obligatory for special buildings, e.g. assembly or sport halls. Further it is not documented that any professional examination of the structural integrity has been carried out as part of the maintenance of the building.

The arena was initially open on two sides. It is not believed that there were any disadvantageous effects from the subsequent enclosure. Neither is a settlement of the concrete structure thought to have caused significant impact on the roof structure.

\section{Robustness considerations}

\subsection{Siemens arena}

During design, it was decided that the $12 \mathrm{~m}$ long purlins between the trusses should only be moderately fastened to the trusses, such that a failure of one truss should not initiate progressive collapse. Each truss then becomes a key element. This strategy proved to work fairly well as "only" 2 of the 12 trusses collapsed. Considering that all trusses had a much lower strength than required it might be fair to conclude that the extent of the collapse was not disproportionate to the cause.

Another, and perhaps more expensive, strategy against progressive collapse could have been to design the trusses, the purlins and their connections such that a failed truss and the roof could hang in the purlins and transfer the load to the neighbouring trusses (when considered an accidental load case). Had this strategy against progressive collapse been chosen, it is most likely that progressive collapse would have occurred because the neighbour trusses could not have withstood the extra load from the truss failing first. In this case, the trusses would not have been key elements.

But had the cause of the failure been a huge load on one truss or a lone standing mistake in one truss, the second strategy would have been preferable because it significantly reduces the risk of injuries. That strategy might also have worked if e.g. a leaking roof had degraded one truss because it is likely that the other trusses remain unharmed. In that case, large deformations would occur, giving a warning of possible failure.

There were two bracing systems in the longitudinal direction, one at each gable. This ensures stability of the remnant part of the building when one truss has failed. This strategy also proved successful, even though there was no wind or snow to call for big demands to the bracing system.

\subsection{Bad Reichenhall ice-arena}

Robustness has not been considered, neither during design nor during the lifetime of the building.

The investigation showed that the first failure occurred in one of the three main girders on the east side. Due to the stiff crossbracing, the loads were shifted from the girder that failêd to the neighbouring girders. Because these girders suffered from the same mistakes and degradation processes as the first failing girder, they could not sustain the additional load. Cô $\equiv$ ently, this developed into a progressive collapse which was seconds.

The ability to redistribute loads, often called redundancy, is generally regarded as favourable for the robustness of a structure because a random local failure will not cause total collapse. This also means that the box-girders are not key elements in the usual meaning of the term. But since the secondary structure was not only strong but also very stiff, a weak girder would transfer its loads to the adjacent girders without any warning from large deformations. This means that e.g. some general finger joints could have lost their strength long ago.

A more robust system could have been achieved in various ways:

- A strong but softer secondary system could give warning about redistribution of load taking place due to increasing deformations. Since the secondary structure also had to fulfil the purpose of bracing against lateral-torsional buckling of the main girders, it needed to be stiff. If both requirements should have been fulfilled, a different bracing system would have been needed.

- A statically determinate secondary system with connections, which would allow for one girder to collapse, without increasing the load on the adjacent girders.

\section{Discussion}

The Siemens arena was a statically determinate structure, whereas the Bad Reichenhall ice-arena was a highly statically indeterminate structure, with a very stiff secondary structural system. It should be noted that neither of the projects for the structures had undergone an independent checking of the design and calculations.

In the Siemens arena the weakness was present from the beginning and quite similar in all trusses. The collapse might have been initialized just by the strength reduction over time. The 
chosen robustness strategy with weak purlins limited the collapse. The design error was so large that it is unlikely that any robustness strategy would have been able to prevent such a collapse, other strategies might even have caused a total collapse. Had it been a local incident which had caused a failure, the collapse might have been restricted to one truss. But nearly $2000 \mathrm{~m}^{2}$ of the roof falling down might in that case have been considered as disproportional to the cause.

In the Bad Reichenhall ice-arena, the weakness was initially much smaller but developed over time, and presumably at different rate in different areas of the roof. The collapse was eventually initialized by a severe but nowhere exceptional snow load. Local damages have most likely been present for a long time, but the stiff structure was able to transfer the load to other parts, without significant deformations. A local incident causing a local failure might therefore never have been revealed. A strategy with a less stiff secondary system would presumably have issued a warning both about the general degradation of the strength as well as damage on a local level.

Large-span timber roof structures generally consist of primary, long spanning members connected by secondary members. The primary members can e.g. be tapered glulam beams, trussed beams or arches. The secondary system is typically realised by a purlintype structure. The purlins carry the roof cladding, which can be regarded as the tertiary structure. In most cases, horizontal loads from wind and torsional loads are carried by a bracing system.

All investigations on failures of large-span timber structures conclude that systematic mistakes during design or construction are the prime reason for failure. It is therefore evident that secondary structures which are able to redistribute loads from a failed main member to neighbouring main members are likely to cause progressive collapse when a main member fails.

Progressive collapse is most efficiently prevented by compartmentalisation of the structure, see [6] this issue. Each compartment can include several main members, but it should not cover an area larger than "acceptable" in the case of failure.

Within a compartment with several main members, the secondary structure can be designed to redistribute loads, so failure of a single primary member will not cause a local collapse. But it is important that such a redistribution becomes immediately evident, e.g. in the form of large deformations. Therefore the secondary system should be designed such that it permits for settlement of the failed member while simultaneously preventing it from collapse. The secondary system should therefore not be too stiff. Another possibility to detect failure could be sophisticated, continuous surveillance systems which give a warning based on deformations or sound from cracks [7].

The area of each compartment might depend on the area of the whole structure, but also on the novelty of the structure. A very innovative design is more likely to inherent systematic errors than traditional structures. For traditional structures, the prevention of local collapse from local failures can be given a higher priority than for innovative structures.

An investigation of the recommendations for robust design in $[8,9]$ shows that they are not very concise and not directly applicable to large-span roof structures. The recommendations in EN 1990 are primarily directed to ensure stability after removal of an element or the introduction of ties. Both are equivalent to redundancy which, as discussed, is not generally desirable for large-span structures. The design of such structures against the hazards specified in [8] would require different, sometimes even conflicting strategies since explosion and impact can be regarded a local effect while human errors will most probably have a repetitive and therefore global effect. EN 1991-1-7 [9] deals primarily with "strategies for limiting the extent of localised failure" of multi-storey buildings. This is obviously not relevant to large-span roof structures where the worst case scenario is systematic errors in the repetitive structural elements.

\section{Conclusion}

The two failure cases demonstrate that redundancy on its own is not suitable for limiting the consequence of failures due to systematic errors and therefore does not ensure robustness of largespan roofs. Only compartmentalisation can ensure that a collapse of such structures does not become progressive. Redundancy on a more local scale can still be obtained in order to minimise the consequence of random errors. Such redundant systems must be designed in a way that it becomes evident if a redistribution of loads has taken place, e.g. by visible deformations. The present recommendations in the Eurocodes focus on redundancy, making them less applicable to large-span roofs.

\section{References}

[1] Hansson M, Larsen HJ. Recent failures in glulam structures and their causes. Engineering Failure Analysis 2005;12(5):808-18.

[2] EN 1995-1-1:2004 + A1:2008. Eurocode 5: design of timber structures - part 1-1: general - common rules and rules for buildings. CEN; 2008.

[3] Hoffmeyer P, Sørensen JD. Duration of load revisited. Wood Science and Technology 2000;41(8):687-711.

[4] Winter S, Kreuzinger H. The Bad Reichenhall ice-arena collapse and the necessary consequences for wide span timber structures. In: Proceedings 10 th world conference on timber engineering. Miyazaki (Japan); 2008.

[5] Schmidt HJ. et al. Überdachung der Eislaufhalle Bad Reichenhall. Ausstellung Holzbau Konstruktionen der Arbeitsgemeinschaft Holz e.V. Düsseldorf als Sonderdruck aus Zeitschrift Detail; 1974/6

[6] Dietsch P. Robustness of large-span timber roof structures - structural aspects. [This issue].

[7] Dietsch P, Köhler J, editors. Assessment of timber structures. Aachen (Germany): Shaker Publishing Company; 2010.

[8] EN 1990:2002. Eurocode: basis of structural design. CEN; 2002.

[9] EN 1991-1-7:2006. Eurocode 1: actions on structures - part 1-7: general actions - accidental actions. CEN; 2006. 